\title{
Thermal effect of Er:YAG and Er,Cr:YSGG used for debonding ceramic and metal orthodontic brackets: An experimental analysis
}

\author{
Patrycja Downarowicz ${ }^{1, A-F}$, Paweł Noszczyk ${ }^{2, A-E}$, Marcin Mikulewicz ${ }^{1, C-F}$, Rafał Nowak ${ }^{3, C, E}$ \\ 1 Department of Facial Abnormalities, Division of Maxillofacial Orthopaedics and Orthodontics, Wroclaw Medical University, Poland \\ ${ }^{2}$ Department of Building Physics and Computer Design Methods, Wroclaw University of Science and Technology, Poland \\ ${ }^{3}$ Department of Maxillofacial Surgery, Wroclaw Medical University, Poland \\ A - research concept and design; $\mathrm{B}$ - collection and/or assembly of data; $\mathrm{C}$ - data analysis and interpretation; \\ $D$ - writing the article; $E$ - critical revision of the article; $F$ - final approval of the article
}

\section{Address for correspondence}

Patrycja Downarowicz

E-mail:p.downarowicz@gmail.com

\section{Funding sources}

None declared

Conflict of interest

None declared

\section{Acknowledgements}

The authors gratefully acknowledge the support of MEDIF Sp. $z$ 0.0. and MARKU DENTAL and their representatives, Aleksander Mieleszko and Grzegorz Fąfara, for providing lasers used in this study.

Received on June 4, 2019

Reviewed on December 11, 2019

Accepted on March 10, 2020

Published online on May 12, 2020

Cite as

Downarowicz P, Noszczyk P, Mikulewicz M, Nowak R. Thermal effect of Er:YAG and Er,Cr:YSGG used for debonding ceramic and metal orthodontic brackets: An experimental analysis. Adv Clin Exp Med. 2020;29(5):557-563.

doi:10.17219/acem/118844

DOI

10.17219/acem/118844

\section{Copyright}

Copyright by Author(s)

This is an article distributed under the terms of the

Creative Commons Attribution 3.0 Unported (CC BY 3.0)

(https://creativecommons.org/licenses/by/3.0/)

\section{Abstract}

Background. In orthodontics, erbium (Er:YAG) lasers can be used for bracket debonding.

Objectives. To assess the changes in temperature of pulp and enamel during laser debonding of brackets.

Material and methods. A total of 13 brackets ( $n=13 ; 2$ metal and 11 ceramic brackets) were bonded to 13 caries-free premolars extracted for orthodontic reasons. Brackets were irradiated with 2 lasers. Laser No. 1 was an erbium-chromium (Er,Cr:YSGG) laser (Waterlase Express; Biolase, Irvine, USA) with a wavelength of 2,780 $\mathrm{nm}$ at a power of 2.78-2.85 W, energy of $185-190 \mathrm{~mJ}$, fluence of $10 \mathrm{~ns}$, frequency of $25 \mathrm{~Hz}$, pulse duration of $300 \mu \mathrm{s}$, tip diameter of $0.6 \mathrm{~mm}$, air/fluid cooling of $3.5 \mathrm{~mL} / \mathrm{s}$, and time of irradiation of $5-25 \mathrm{~s}$. Laser No. 2 was an Er:YAG laser (LiteTouch; Light Instruments Ltd., Yokneam, Israel) with a wavelength of 2,940 $\mathrm{nm}$ at a power of $4 \mathrm{~W}$, energy of $200 \mathrm{~mJ}$, fluence of $10 \mathrm{~ns}$, frequency of $20 \mathrm{~Hz}$, pulse duration of $300 \mathrm{\mu s}$, tip diameter of $0.8 \mathrm{~mm}$, air/fluid cooling of $3.5 \mathrm{~mL} / \mathrm{s}$, and time of irradiation of 5-15 s. Two thermographic cameras (FLIR Zenmuse XT and FLIR P65; FLIR Systems, Wilsonville, USA) and type K thermocouple (Zhangzhou Weihua Electronic Co., Fujian, China) were used for precise temperature measurement on the surface of the teeth and inside them.

Results. When laser No. 1 was in use, the mean difference between the inner and outer temperature of the examined teeth $\left(1.4^{\circ} \mathrm{C}\right)$ was higher than when the laser No. 2 was in use $\left(0.6^{\circ} \mathrm{C}\right)(p=0.0974)$. The study found that the temperature inside the tooth did not increase, and it even decreased during treatment with Er:YAG laser using water cooling, provided that appropriate proportion of water and air was used. For laser No. 1, confidence interval (Cl) was between 0.7 and 2.2 and for laser №. 2 it was between 0.500 and 1.23. Only experiment for ceramic brackets was described.

Conclusions. These findings confirm that the use of Er:YAG family lasers for orthodontic bracket debonding in an in vitro study is safe and effective.

Key words: thermography, enamel, orthodontic treatment, thermocouple, tooth temperature 


\section{Introduction}

Lasers are used in all areas of dentistry, ranging from the treatment of soft and hard tissues, periodontal and peri-implant therapy, infections caused by bacteria and fungi, to orthodontic treatment. ${ }^{1-6}$

Orthodontic treatment using fixed appliances with metal or ceramic brackets is a common therapy of malocclusion. ${ }^{7}$ Removal of the bracket with conventional debonding pliers, however, can results in enamel cracks, pain and ceramic bracket damage. ${ }^{8}$ The available single reports of in vitro studies using the 2,940 $\mathrm{nm}$ wavelength erbium (Er:YAG) lasers for ceramic bracket debonding indicate that the procedure is effective and safe for the pulp and enamel. ${ }^{9-14}$ Lasers are effective in softening the adhesion at the bracket/resin interface by producing heat energy. Energy transfers into heat within the bonding material vapor and debond the brackets from the enamel. ${ }^{9}$ Therefore, problems such as enamel break, bracket detachment and pain during debonding can be solved. The literature concerning the effect of the 2,780 nm wavelength erbium-chromium lasers (Er,Cr:YSGG) is scarce. ${ }^{15}$ In addition, lasers have such advantages as decreasing debonding force and shortening debonding time. ${ }^{16}$ The Er:YAG laser $(2,940 \mathrm{~nm})$ has a high absorbance coefficient in water. ${ }^{17}$ Particular care should be taken to prevent thermal injury of the dental pulp with high-power lasers. ${ }^{18}$ For example, an intrapulpal increase of $5.5^{\circ} \mathrm{C}$ causes pulpitis or pulp necrosis in $15 \%$ of irradiated teeth. ${ }^{19}$ A temperature increase by $10^{\circ} \mathrm{C}$ on the outer root surfaces causes bone resorption and tooth ankylosis. ${ }^{20}$ The use of high-power lasers requires welldefined parameters to prevent thermal damage and to ensure predictable debonding of brackets. However, there is no data on the effect of the 2,780 nm wavelength Er:YAG laser.

The objective of the research was to assess the changes in temperature of pulp and enamel during laser debonding of ceramic and metal brackets.

\section{Material and methods}

\section{Sample preparation}

Thirteen healthy human premolars, extracted as a part of orthodontic treatment, were immersed in 5\% formalin solution for $24 \mathrm{~h}$. All the teeth were removed on the same day before the experiment. They were kept at stable room temperature. After the 24-hour immersion, the enamel surface was polished with fluoride-free polishing paste (Super Polish; Kerr Hawe, Brea, USA) using the handpieceattached prophy brush, rinsed and air-dried.

\section{Bracket bonding procedure}

Prior to laser exposure, metal (Mini Diamond Twin; Ormco, Glendora, USA) and esthetic (Inspire-ICE; Ormco) brackets were bonded (Primer Transbond XT and
Transbond XT; 3M Unitek, Maplewood, USA) on the same day. The polymerization of orthodontic adhesive was carried out for $20 \mathrm{~s}$ using a LED light-curing device. Next, the study teeth were immersed in a $5 \%$ formalin solution once again at stable room temperature for $48 \mathrm{~h}$ to ensure that bonding was complete prior to bracket debonding. Pulpectomy was performed in most studied teeth and pulp replaced with thermal compound to enable temperature measurements using a thermocouple within a pulp cavity. Tooth preparation protocol is shown in Fig. 1.

\section{Debonding protocol}

This experimental in vitro study yielded specific settings of 2 lasers.

Laser No. 1 - Er,Cr:YSGG laser (Waterlase Express; Biolase, Irvine, USA) with a 2,780 nm wavelength, power of 2.78-2.85 W, energy of 185-190 mJ, frequency of $25 \mathrm{~Hz}$, pulse duration of $300 \mu \mathrm{s}$, tip diameter of $0.6 \mathrm{~mm}$, air/fluid cooling of $3.5 \mathrm{~mL} / \mathrm{s}$, and illumination time until spontaneous ceramic bracket detachment of 5-25 s.

Laser No. 2 - Er:YAG laser (LiteTouch; Light Instruments Ltd., Yokneam, Israel) with a 2,940 nm wavelength, power of $4 \mathrm{~W}$, energy of $200 \mathrm{~mJ}$, frequency of $20 \mathrm{~Hz}$, pulse duration of $300 \mu \mathrm{s}$, tip diameter of $0.8 \mathrm{~mm}$, air/fluid cooling
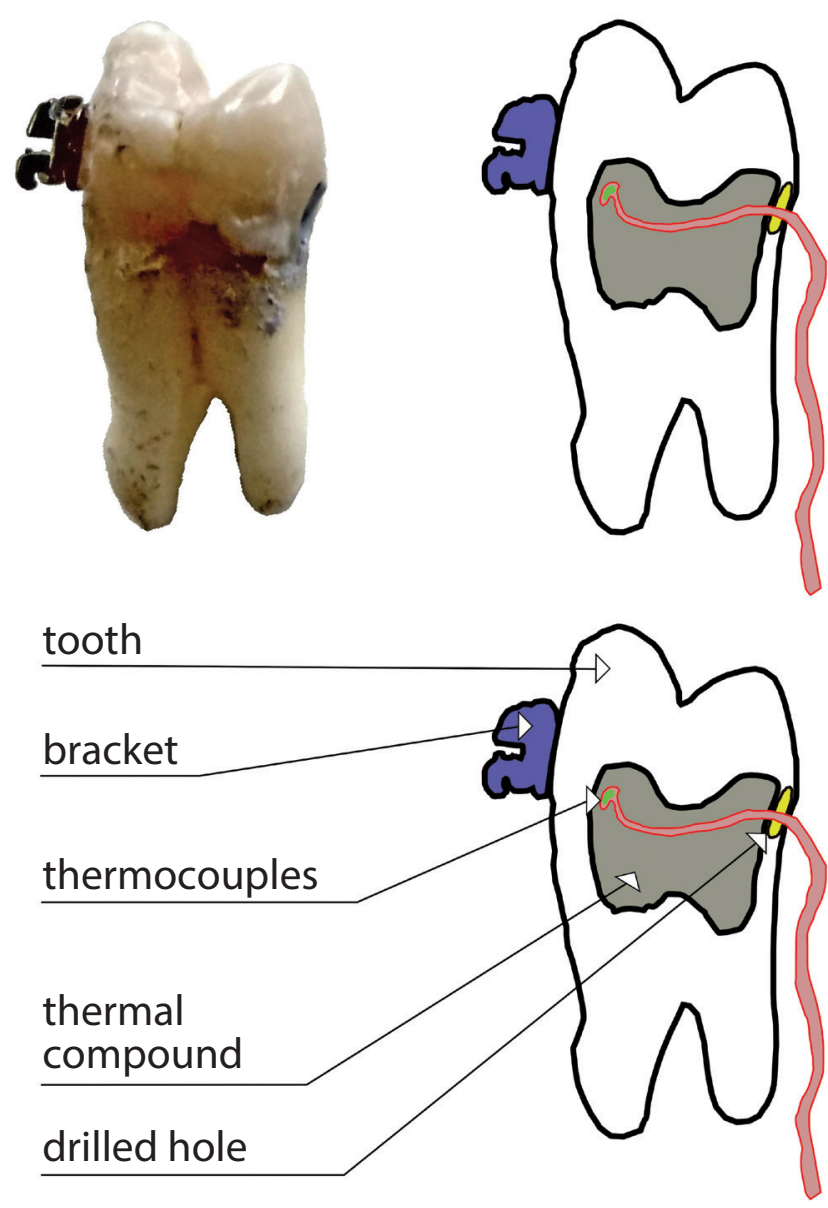

Fig. 1. Tooth preparation protocol 
of $3.5 \mathrm{~mL} / \mathrm{s}$, and illumination time until spontaneous ceramic bracket detachment of 5-15 s.

The laser energy was applied from a distance of 1-2 mm. Ceramic brackets were illuminated centrally and with slight circular motion, whereas metal brackets were irradiated from all sides. All the samples were debonded with Er:YAG and Er;Cr:YSGG lasers on the same day.

\section{Temperature measurement}

The temperature measurement followed a three-step procedure:

- temperature measurement prior to switching on the laser (20 s);

- temperature measurement during laser exposure. The exposure was continued either over a predefined amount of time or until the bracket detached, whichever shorter. This step lasted between $5 \mathrm{~s}$ and $150 \mathrm{~s}$;

- temperature measurement after the laser was switched off, as the thermal balance between the tooth and the environment was being restored. This step lasted for a few minutes.

During each step of the procedure, the temperature on the surface of the tooth was measured using the thermographic camera every $10 \mathrm{~s}$, whereas the temperature inside the tooth was measured using a thermocouple every $1 \mathrm{~s}$.
If the bracket did not detach spontaneously within a few minutes following laser exposure, manual debonding was attempted. A following test stand was designed: 2 thermographic cameras, i.e., FLIR Zenmuse XT (FLIR Systems, Wilsonville USA) with a $640 \times 512$ pixel resolution and thermal sensitivity $<50 \mathrm{mK}$, and FLIR P65 camera (FLIR Systems) with a $320 \times 240$ pixel resolution and thermal sensitivity < $80 \mathrm{mK}$; relative humidity and ambient temperature sensor; and a temperature sensor attached to type K thermocouples (Zhangzhou Weihua Electronic Co., Fujian, China) (Fig. 1). The measurements recorded under different conditions are shown in Table 1.

\section{Statistical analysis}

The obtained outcomes were subject to statistical analysis using STATISTICA v. 12.0 (StatSoft, Inc., Tulsa, USA) software and Student's t-test $(\mathrm{p}=0.0974)$. The test for the assessment of normality was Kolmogorov-Smirnov (K-S).

\section{Results}

When laser No. 1 was used, the outside temperature of the examined teeth $\left(23.3^{\circ} \mathrm{C}\right)$ was significantly higher than their inner temperature $\left(21.4^{\circ} \mathrm{C}\right)(\mathrm{p}=0.0004)$. Using

Table 1. The measurements performed under different conditions.

\begin{tabular}{|c|c|c|c|c|c|c|c|c|}
\hline 1 & 2 & 3 & 4 & 5 & 6 & 7 & 8 & 9 \\
\hline $\begin{array}{l}\text { Tooth } \\
\text { No. }\end{array}$ & $\begin{array}{l}\text { laser exposure } \\
\text { duration }\end{array}$ & energy & power & frequency & $\begin{array}{l}\text { amount } \\
\text { of water* }\end{array}$ & $\begin{array}{l}\text { amount } \\
\text { of air }\end{array}$ & bracket debonding & bracket type \\
\hline$[-]$ & {$[s]$} & {$[\mathrm{mJ}]$} & {$[\mathrm{W}]$} & {$[\mathrm{Hz}]$} & [\%] & [\%] & {$[-]$} & {$[-]$} \\
\hline 1 & 30 & 120 & 3 & 25 & 5 & 10 & manual, medium force & ceramic \\
\hline 2 & 30 & 120 & 3 & 25 & 5 & 10 & manual, medium force & ceramic \\
\hline 3 & 30 & 120 & 3 & 25 & 0 & 10 & manual, medium force & ceramic \\
\hline 4 & 15 & 180 & 2.7 & 25 & 80 & 60 & manual, medium force & ceramic \\
\hline 5 & 10 & 190 & 2.85 & 25 & 80 & 60 & detached spontaneously & ceramic \\
\hline 6 & 25 & 185 & 2.78 & 25 & 80 & 60 & manual, low force & ceramic \\
\hline 7 & 5 & 185 & 2.78 & 25 & 80 & 60 & detached spontaneously & ceramic \\
\hline \multicolumn{9}{|c|}{ Laser No. 2 - Little Touch, Er:YAG, 2,940 nm (2.94 um) wavelength } \\
\hline 1 & 2 & 3 & 4 & 5 & 6 & 7 & 8 & 9 \\
\hline $\begin{array}{l}\text { Tooth } \\
\text { No. }\end{array}$ & $\begin{array}{l}\text { laser exposure } \\
\text { duration }\end{array}$ & energy & power & frequency & $\begin{array}{l}\text { amount of water } \\
\text { and air* }\end{array}$ & nozzle type & bracket debonding & bracket type \\
\hline$[-]$ & {$[\mathrm{s}]$} & {$[\mathrm{mJ}]$} & {$[\mathrm{W}]$} & {$[\mathrm{Hz}]$} & {$[\%]$} & {$[-]$} & {$[-]$} & {$[-]$} \\
\hline 8 & 15 & 200 & 4 & 20 & 50 & red & detached spontaneously & ceramic \\
\hline $9^{\ll}$ & 15 & 200 & 4 & 20 & 50 & red & detached spontaneously & ceramic \\
\hline 10 & 75 & 200 & 4 & 20 & 50 & yellow & manual, low force & ceramic \\
\hline 11 & 5 & 200 & 4 & 20 & 50 & red & detached spontaneously & ceramic \\
\hline 12 & 120 & 200 & 4 & 20 & 50 & red & manual, did not detach & metal \\
\hline 13 & 120 & 500 & 7.5 & 15 & 50 & black & manual, did not detach & metal \\
\hline
\end{tabular}

* $100 \%$ of air or water denotes maximum amount for a given device; ** the tooth was not filled with thermal compound - the pulp was not removed. 
laser No. 2, the outside temperature of the examined teeth $\left(24.7^{\circ} \mathrm{C}\right)$ was slightly higher than their inner temperature $\left(24.2^{\circ} \mathrm{C}\right)(\mathrm{p}=0.1004)$. When using laser No. 1 , the median difference between the inner and outer temperatures of the examined teeth $\left(1.4^{\circ} \mathrm{C}\right)$ was higher than when laser No. 2 was used $\left(0.6^{\circ} \mathrm{C}\right)(\mathrm{p}=0.0974)$.

The temperature changes over time both on the surface of the teeth and inside the teeth are presented in the Figures below. The temperature inside the tooth was shown in Fig. 2 and 3. Figures 4 and 5 show temperature values measured on the surface of the teeth using the FLIR P65 thermographic camera (the Zenmuse XT thermographic camera was an additional, control camera). The temperature differences between the enamel and the pulp at the same time points were computed. Positive numbers indicate that the temperature of the enamel was higher than that of the pulp. The results are shown in Fig. 6 and 7.

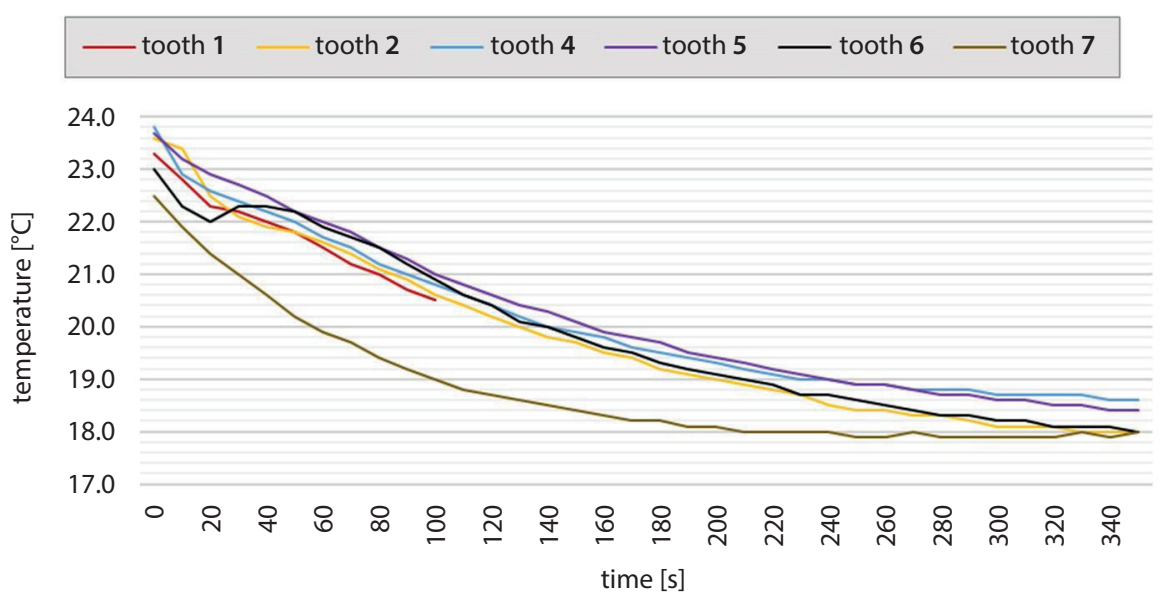

Fig. 2. The temperature inside the tooth during treatment with laser No. 1 measured using thermocouple - diagram close-up
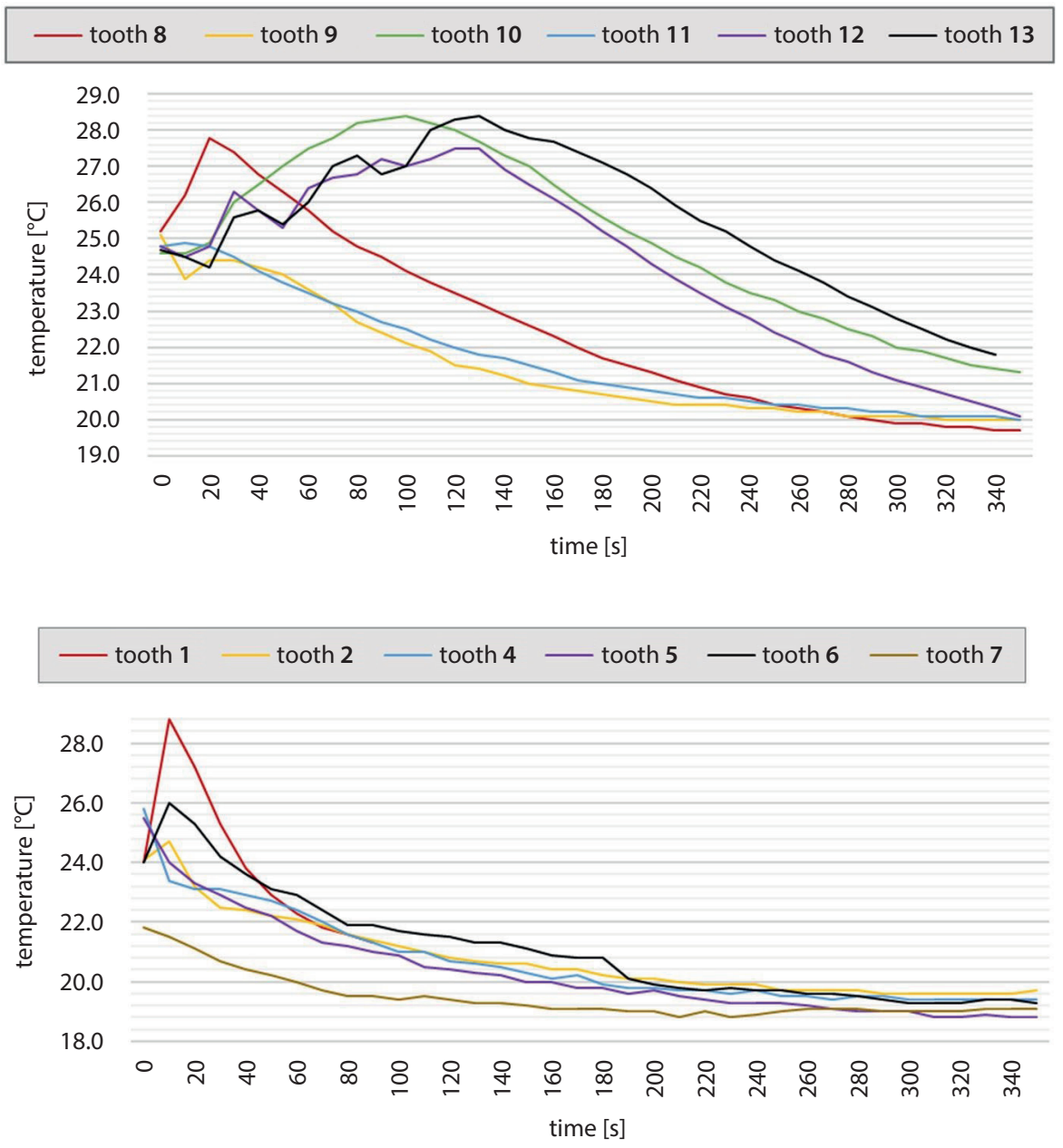

Fig. 3. The temperature inside the tooth during treatment with laser No. 2 measured using thermocouple

Fig. 4. The temperature on the surface of the tooth during treatment with laser No. 1 measured using thermographic camera - diagram close-up 


\begin{tabular}{llll|}
\hline tooth $8 \quad$ tooth $9 \quad$ tooth $10 \quad$ tooth $11 \quad$ tooth 12 \\
\hline
\end{tabular}

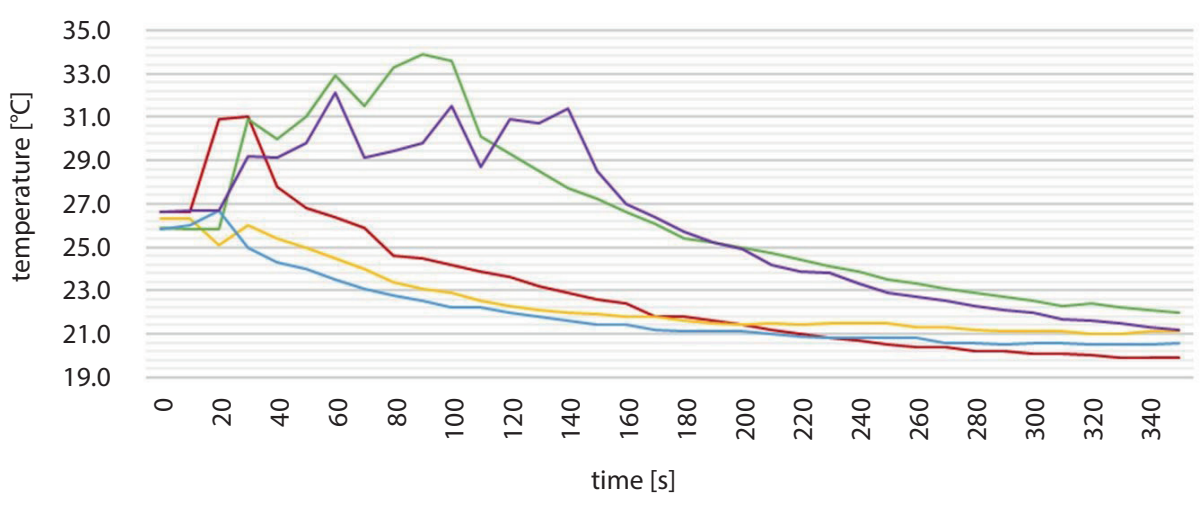

Fig. 5. The temperature on the surface of the tooth during treatment with laser No. 2 measured using thermographic camera - diagram close-up
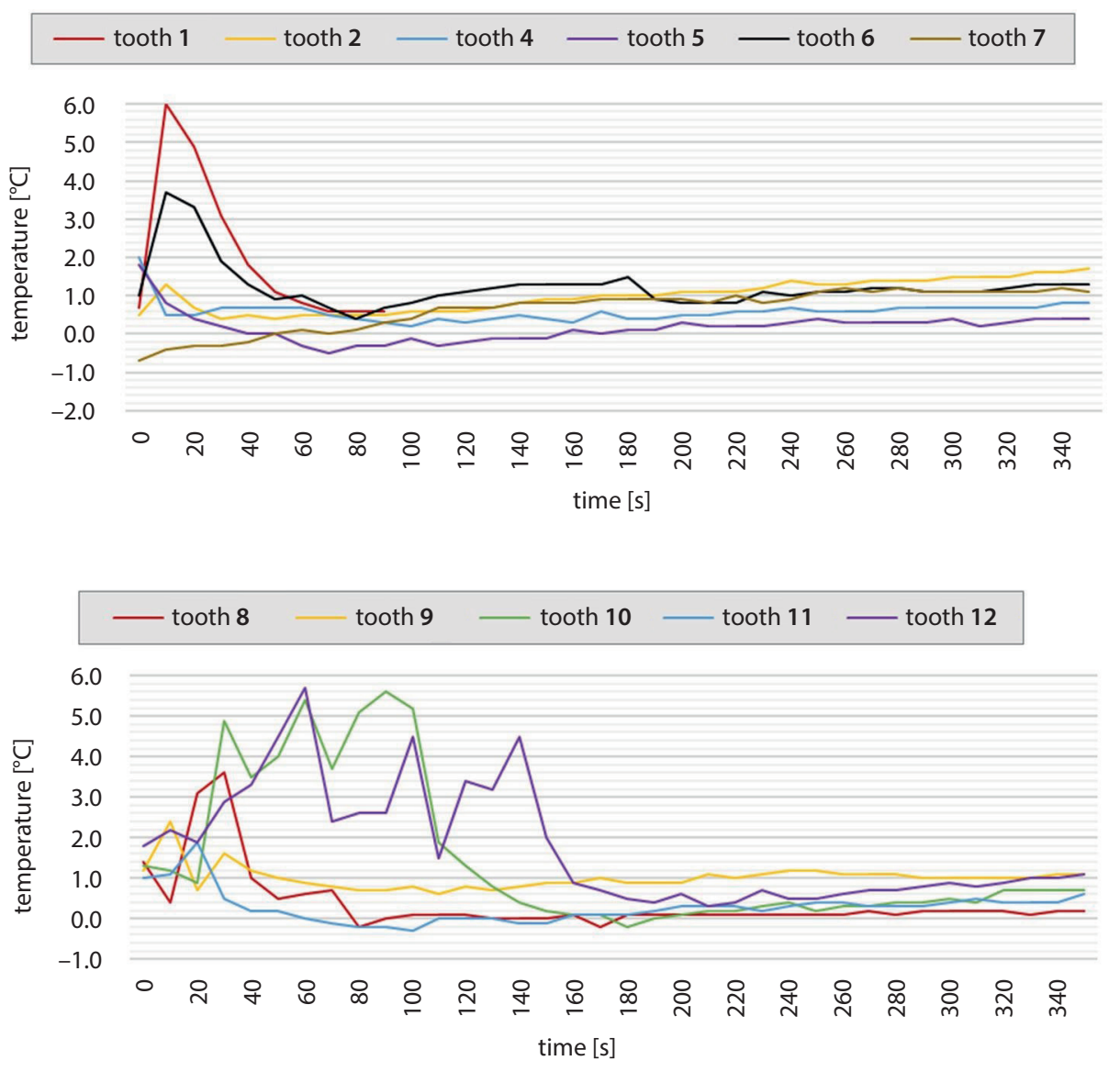

Fig. 6. Temperature differences between the enamel and pulp during exposure to laser No. 1 - diagram close-up
Fig. 7. Temperature differences between the enamel and pulp during exposure to laser No. 2 - diagram close-up
We found that laser debonding has caused lower temperature increase in dental pulp, which is a very good prognostic tool for in vivo study.

Our study described only the experiment for ceramic brackets.

The authors tried to debond 8 metal brackets using Er:YAG (4 brackets) and ER,Cr:YSGG (4 brackets) lasers, but neither debonded at any time (brackets were illuminated from all sides for 10-300 s). In our study, metal brackets were impossible to debond and that was the cause why the temperature was not checked. Only 2 metal brackets were measured to check the temperature.

\section{Discussion}

The application of a laser for debonding orthodontic brackets has been investigated with regard to different wavelength $s^{13,17}$ and to different types of brackets, types of adhesive materials and lasing methods. ${ }^{13,20}$ Our study contributes to the existing knowledge by testing the use of Er:YAG laser at the indicated parameters. Such laser supports debonding of dental brackets without significant damage to the dental pulp. Hamadah et al. used the $4.2 \mathrm{~W}$ laser power for $6 \mathrm{~s}$ in order to debond ceramic brackets and observed a temperature increase of $2.91-3.35^{\circ} \mathrm{C} .^{10}$ 
Nalbantgil et al., who used the $5 \mathrm{~W}$ Er:YAG laser power for $9 \mathrm{~s}$ on orthodontic brackets with and without water cooling, obtained similar results. ${ }^{11}$ They reported that in the group with water cooling, the pulp temperature increase was lower (about $2.41^{\circ} \mathrm{C}$ ) than in the group without water cooling (about $4.59^{\circ} \mathrm{C}$ ). This has shown that simultaneous cooling the tooth surface with water spray is a necessary prerequisite for safe and effective debonding of orthodontic brackets. Dostálová et al. ${ }^{12}$ concluded that there is a temperature increase of $2.0-3.2^{\circ} \mathrm{C}$ during laser debonding of both metal and ceramic brackets. The Er:YAG laser energy of $280 \mathrm{~mJ}$ was applied for $140 \mathrm{~s}$ at the frequency of $6 \mathrm{~Hz}$. A temperature increase observed during debonding of metal brackets was lower than during the debonding of ceramic ones. An even lower temperature increase was observed following debonding of ceramic brackets using a new scanning laser method. There is no information in literature about the thermal effect of Er,Cr:YSGG laser used for debonding orthodontic brackets. In the study conducted by Zach and Cohen, the authors demonstrated that there is a pulp temperature increase of $1.8^{\circ} \mathrm{C}$ during laser bracket debonding. ${ }^{19}$ Thus, they proved that laser debonding is safe for vital teeth, as only an increase of $5.5^{\circ} \mathrm{C}$ or more can cause pulpitis or pulp necrosis in $15 \%$ of laser-treated teeth. According to the newest research by Grzech-Leśniak et al., ceramic and metal brackets can be debonded using a laser at specific, predefined settings. ${ }^{9}$ In this study, Er:YAG laser irradiation was associated with a slight, statistically nonsignificant increase in temperature during the orthodontic brackets debonding. These outcomes were statistically significantly higher in comparison with the ceramic brackets debonded using the scanning technique $(\mathrm{p}=0.015)$. The mean temperature gradient obtained for metal brackets was lower than for ceramic brackets. However, further in vivo studies are warranted to assess the impact of lasers on the rise of the temperature in the tooth and on the surface structure of the teeth as well.

The study contributes to the existing knowledge by testing the use of Er:YAG laser in ceramic and metal brackets debonding. The main finding of the study was that the Er:YAG laser supports debonding of dental brackets without significant damage to the enamel or the dental pulp. Findings regarding the use of the Er:YAG laser at the indicated parameters are important because of efficiency and safety of debonding.

The Er:YAG and Er,Cr:YSGG laser wavelengths both operate in the region of the major absorption peak for water and are the most suited to hard-tissue ablation treatments. The Er:YAG laser wavelength penetrates about $7 \mu \mathrm{m}$ into the enamel and $5 \mu \mathrm{m}$ into the dentin. The Er,Cr:YSGG laser wavelength penetrates deeper $-21 \mu \mathrm{m}$ into the enamel and $15 \mu \mathrm{m}$ into the dentin. Because of the higher absorption, the Er:YAG laser has a smaller penetration depth, and therefore, requires less time to ablate the tissue. ${ }^{21}$
Protecting the pulp is very important during debonding. Within the limitation of our ex vivo study, the outcomes suggest that it is safe to use lasers from the Er:YAG family during the removal of ceramic brackets. In our study, metal brackets were impossible to remove using lasers.

\section{Conclusions}

The studied Er:YAG family lasers of 2 different wavelengths can be safely used for orthodontic bracket debonding with air and water cooling only.

During the treatment with laser No. 1 with cooling, not only did the temperature inside the tooth fail to increase, but it actually decreased, which appears promising for its potential in vivo use in the oral cavity. A temperature increase (up to about $3^{\circ} \mathrm{C}$ ) followed by a subsequent drop was observed during the first stage of treatment with laser No. 2.

Ceramic brackets detach spontaneously significantly more often than metal brackets when using discussed laser parameters.

\section{ORCID iDs}

Patrycja Downarowicz (D) https://orcid.org/0000-0001-5411-4669 Paweł Noszczyk (D) https://orcid.org/0000-0003-2810-5165 Marcin Mikulewicz (D) https://orcid.org/0000-0001-5754-0284 Rafał Nowak (D) https://orcid.org/0000-0001-9375-0369

\section{References}

1. Grzech-Leśniak K. Making use of lasers in periodontal treatment: A new gold standard? Photomed Laser Surg. 2017;35(10):513-514.

2. Mizutani K, Aoki A, Coluzzi D, et al. Lasers in minimally invasive periodontal and peri-implant therapy. Periodontol 2000. 2016;71(1):185-216.

3. Grzech-Leśniak K, Sculean A, Gaspirc B. Laser reduction of specific microorganisms in the periodontal pocket using Er:YAG and Nd:YAG lasers: A randomized controlled clinical study. Lasers Med Sci. 2018; 33:1461-1470.

4. Grzech-Leśniak K, Matys J, Dominiak M. Comparison of clinical and microbiological effects of antibiotic therapy in periodontal pockets following laser treatment: In vivo study. Adv Clin Exp Med. 2018;27(9): 1263-1270.

5. Grzech-Leśniak K, Nowicka J, Pajączkowska M, et al. Effects of Nd:YAG laser irradiation on the growth of Candida albicans and Streptococcus mutans: In vitro study. Lasers Med Sci. 2019;34(1):129-137.

6. Grzech-Leśniak K, Bericharit S, Dalal N, Mroczka K, Deeb JG. In vitro examination of the use of Er:YAG laser to retrieve lithium disilicate crowns from titanium implant abutments. J Prosthodont. 2019;28(6): 672-676. doi:10.1111/jopr.13077

7. Nishimura M, Sannohe M, Nagasaka H, Igarashi K, Sugawara J. Nonextraction treatment with temporary skeletal anchorage devices to correct a class II division 2 malocclusion with excessive gingival display. Am J Orthod Dentofacial Orthop. 2014;145(1):85-94.

8. Soltani MK, Barkhori S, Alizadeh Y, Golfeshan F. Comparison of debonding characteristics of the conventional metal and self-ligating brackets to enamel: An in vitro study. Iran J Orthod. 2014;9(3):e4842. doi:10.17795/ijo-3739

9. Grzech-Leśniak K, Matys J, Żmuda-Stachowiak D, et al. Er:YAG laser for metal and ceramic bracket debonding: An in vitro study on intrapulpal temperature. SEM and EDS analysis. Photomed Laser Surg. 2018; 36(11):595-600.

10. Hamadah O, Bachir W, Zamzam MK. Thermal effect of Er:YAG laser pulse durations on teeth during ceramic bracket debonding. Dent Med Probl. 2016;53(3):352-357. 
11. Nalbantgil D, Tozlu M, Oztoprak MO. Pulpal thermal changes following Er:YAG laser debonding of ceramic brackets. Sci World J. 2014; 2014:912429. doi:10.1155/2014/912429

12. Dostálová T, Jelínková H, Remes $M$, Šulc J, Nemec M. The use of the Er:YAG laser for bracket debonding and its effect on enamel damage. Photomed Laser Surg. 2016;34(9):394-399.

13. Dostálová T, Jelínková $\mathrm{H}$, Šulc J, et al. Laser brackets debonding: Tm:YAP, Nd:YAG, and GaAs diode lasers evaluation. Lasers in Dentistry. 2009;XV 7162:71620C-71620C-6. doi:10.1117/12.808137

14. Sohrabi A, Jafari S, Kimyai S, Rikhtehgaran S. Er,Cr:YSGG laser as a novel method for rebonding failed ceramic brackets. Photomed Laser Surg. 2016;34(10):483-486.

15. Mirhashemi AH, Chiniforush N, Sharifi N, Hosseini AM. Comparative efficacy of Er,Cr:YSGG and Er:YAG lasers for etching of composite for orthodontic bracket bonding. Lasers Med Sci. 2018;33(4):835-841.
16. Sabuncuoglu FA, Ersahan S, Erturk E. Debonding of ceramic brackets by Er:YAG laser. J Istanb Univ Fac Dent. 2016;50(2):24-30.

17. Eriksson AR, Albrektsson T. Temperature threshold levels for heatinduced bone tissue injury: A vital microscopic study in the rabbit. J Prosthet Dent. 1983;50(1):101-107.

18. Stein S, Kleye A, Schauseil M, Hellak A, Korbmacher-Steiner H, Braun A. 445- $\mathrm{nm}$ diode laser-assisted debonding of self-ligating ceramic brackets. Biomed Tech (Berl). 2017;62(5):513-520. doi:10.1515/bmt2016-0027

19. Zach L, Cohen G. Pulp response to externally applied heat. Oral Surg Oral Med Oral Pathol. 1965;19:515-530.

20. Ozcan M, Finnema K, Ybema A. Evaluation of failure characteristics and bond strength after ceramic and polycarbonate bracket debonding: Effect of bracket base silanization. Eur J Orthod. 2008;30(2):176-182.

21. Diaci J, Gaspirc B. Comparison of Er:YAG and Er,Cr:YSGG lasers used in dentistry. Journal of the Laser and Health Academy. 2012;1:1-13. 